\title{
25. COMPRESSIONAL SOUND VELOCITIES IN SEMI-INDURATED SEDIMENTS AND BASALTS FROM DSDP LEG $11^{1}$
}

\author{
Edward Schreiber, Department of Earth and Environmental Sciences, Queens College, Flushing, N. Y. \\ and Lamont-Doherty Geological Observatory, Palisades, N. Y., \\ P. J. Fox, Lamont-Doherty Geological Observatory, Palisades, N. Y., and \\ Joseph Peterson, Department of Earth and Environmental Sciences, Queens College, Flushing, N. Y.
}

\section{INTRODUCTION}

Rock specimens recovered from the ocean floor have always been studied with some excitement. This is especially so for the material recovered by the Deep Sea Drilling Project, because the significance of the samples is enhanced by a more exact knowledge of location, orientation; and bedding sequence than is available for rocks that are dredged. Igneous basement was penetrated and basaltic rocks were recovered from several of the sites drilled during Leg 11. In view of the still unsolved problem concerning the composition and structure of the oceanic crust, these specimens were of particular interest.

Within and beneath the sedimentary cover, acoustic horizons have been recognized which have been found to be extensive and continuous. The exact nature of these horizons, however, remains to be determined. A principal datum in defining these horizons is the sound velocity in the overlying and underlying layers. Therefore, the measured velocity of sound propagated through rock specimens is one of the principal parameters for correlating a rock type with an acoustically determined layer of unknown composition. For this reason we have measured the velocity of compressional waves traveling through samples of the basalt and semi-indurated sediment recovered during Leg 11 .

\section{SAMPLES AND METHOD}

\section{Samples}

Basaltic rocks were recovered in Sites 100 and 105. Selection of samples was random, since our purpose at this stage was to survey the rocks, and focus on particular problems as we came across them. Using a small ( 0.5 inch I.D.) diamond corer, specimens 1 to 2

\footnotetext{
${ }^{1}$ Lamont-Doherty Geological Observatory Contribution No. 1658.

${ }^{2}$ Birch (1964) used a calibrated mercury column, relating the velocity of sound in the specimen to the known velocity of sound in mercury and the length of a mercury column required to match the transit time of sound through the specimen.
}

inches long were taken in directions parallel to and perpendicular to the drilling axis of the core. The ends of each specimen were cut smooth and parallel to within 0.001 inch of each other, to form a right circular cylinder. The cylinder was completely encased with a copper jacket 0.002 millimeter-thick, the joints were solder-sealed, and a transducer was glued to each end of the cylinder. The purpose of the jacket was to prevent the pressure-generating fluid from entering the pores and cracks in the specimen. The basalt samples studied are listed in Table 1.

Semi-indurated, late Jurassic to early Cretaceous sediment specimens from Sites 100 and 105 were also prepared (Table 2). These specimens were sampled and prepared in the "as stored" condition, and contained

TABLE 1

Specimens of Basalt Used in This Investigation

\begin{tabular}{ccc}
\hline $\begin{array}{c}\text { Samplea } \\
\text { (Site-Core-Section) }\end{array}$ & $\begin{array}{c}\text { Depth in Core } \\
(\mathrm{cm})\end{array}$ & $\begin{array}{c}\text { Sample Length } \\
(\mathrm{cm})\end{array}$ \\
\hline $100-11-1 \mathrm{~A}$ & $48-54$ & 3.543 \\
$100-12-1 \mathrm{~A}$ & $128-132$ & 4.305 \\
$100-12-1 \mathrm{~B}$ & $128-128$ & 4.325 \\
$100-13-2 \mathrm{~A}$ & $97-101$ & 3.124 \\
$100-13-2 \mathrm{~B}$ & $105-105$ & 3.558 \\
$100-13-1 \mathrm{~A}$ & $140-145$ & 4.318 \\
$100-13-1 \mathrm{~B}$ & $148-148$ & 4.343 \\
$105-41-1 \mathrm{~A}$ & $10-14$ & 3.578 \\
$105-41-1 \mathrm{~B}$ & $16-16$ & 3.134 \\
$105-41-3 \mathrm{~A}$ & $0-5$ & 3.558 \\
$105-41-3 \mathrm{~B}$ & $8-8$ & 4.305 \\
$105-42-2 \mathrm{~A}$ & $82-85$ & 3.134 \\
$105-43-2 \mathrm{~A}$ & $90-95$ & 4.302 \\
$105-43-2 \mathrm{~B}$ & $97-97$ & 4.338 \\
& & \\
\hline
\end{tabular}

aIn the A samples the specimen axis is parallel to the drilling axis; in the B samples the specimen axis is normal to the drilling axis. 
TABLE 2

Specimens of Sediments Used in This Investigation

\begin{tabular}{cclc}
\hline $\begin{array}{c}\text { Samplea } \\
\text { (Site-Core-Section) }\end{array}$ & $\begin{array}{c}\text { Depth } \\
\text { in Core } \\
(\mathrm{cm})\end{array}$ & \multicolumn{1}{c}{ Age } & $\begin{array}{c}\text { Sample } \\
\text { Length } \\
(\mathrm{cm})\end{array}$ \\
\hline $100-3-1 \mathrm{~A}$ & $66-71$ & Late Jurassic & 5.37 \\
$100-7-1 \mathrm{~A}$ & $31-37$ & Late Jurassic & 3.88 \\
$100-8-3 \mathrm{~A}$ & $110-113$ & Late Jurassic & 2.92 \\
$105-17-3 \mathrm{~A}$ & $86-90$ & Early Cretaceous & 4.28 \\
$105-17-3 \mathrm{~B}$ & $90-92$ & Early Cretaceous & 4.20 \\
$105-25-2 \mathrm{~A}$ & $19-21$ & Early Cretaceous & 3.07 \\
$105-25-2 \mathrm{~B}$ & $38-42$ & Early Cretaceous & 3.61 \\
$105-33-1 \mathrm{~A}$ & $78-84$ & Late Jurassic & 3.28 \\
$105-35-4 \mathrm{~A}$ & $35-39$ & Late Jurassic & 4.40 \\
$105-39-1 \mathrm{~A}$ & $88-93$ & Late Jurassic & 4.77 \\
\hline
\end{tabular}

aIn the A samples the specimen is parallel to the drilling axis; in the B samples the specimen is normal to the drilling axis.

pore water of undetermined amount. Because these materials are soft, they were shaped by hand to form specimens of geometry similar to that of the basalts, and completely encased in a copper jacket as described above. However, epoxy was used to seal the jacket instead of solder.

\section{Method}

The usual method employed for determining travel time of sound waves passing through rocks is based upon the pulse transmission method used by Birch $(1960)^{2}$. A variation of that method was used here. The main difference between our technique and others is in the measurement of the time interval required for the sound wave to transit the length of the specimen. As described in Mattaboni and Schreiber (1967), we use an electronically generated scaling wave, the period of which is some submultiple of the transit time through the specimen. Figure 1 is a photograph of the oscilloscope display as seen during a measurement. At the left on the lower trace is the initiating pulse applied to one transducer, and the signal received by the transducer at the other end of the specimen is at the right. The scaling wave is displayed on the upper trace, and the frequency of this wave is adjusted until an exact integral number of cycles fits between the applied and received signals. This value is read from a frequency counter, and together with the length of the specimen, the velocity of sound is calculated.

The velocity of sound through rocks is sensitive to the presence of pores and cracks, and the exact way in which velocity changes with porosity is sensitive to the shape of the pore or crack (see for example, Walsh,

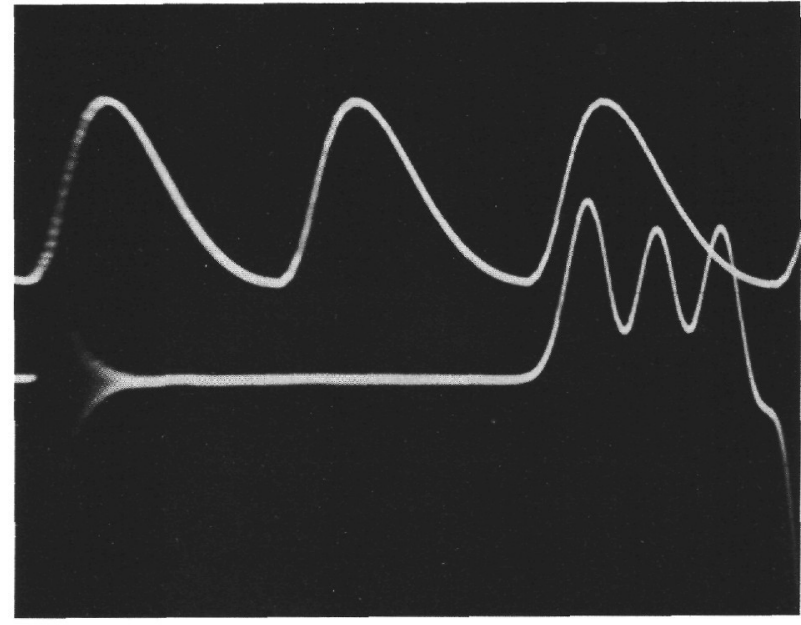

Figure 1. Photograph of the oscilloscope display as seen during a measurement. See text for explanation.

1965; Warren, 1970). Typically, rocks have thin, elongated cracks, and the measured velocity drops rapidly with the presence of a small number of these imperfections. Consequently, the velocity measured under atmospheric pressure is not representative of the in situ velocity. Therefore, velocity of sound through rocks is measured as a function of hydrostatic pressure. As the cracks and pores close, velocity increases, and approaches the intrinsic value for a given rock. As an example, a curve for one of the basalt samples measured during this investigation is shown in Figure 2. The velocity increases rapidly with applied pressure and then levels off as it approaches an intrinsic limiting value. A hysteresis effect is frequently displayed by the pressure velocity data. This may be due to permanent changes in the fracture system in the rock which develop as pressure is released.

Pressure runs were made to 6 kilobars. The transducers were wired to leads passing through the closure of the pressure vessel. A mixture of kerosene and petroleum ether was used as the pressurizing fluid since it does not freeze at the pressures employed. Pressures were read on a gauge accurate to 0.1 per cent of full scale (that is, 0.1 per cent of 7000 bars).

\section{RESULTS AND DISCUSSION}

The results of measurements performed on 14 samples of basalt prepared from the cores are given in Table 3 , where velocity is reported as a function of pressure. To obtain the values presented in Table 3 , a smooth curve was fitted to the data, and the velocity at a pressure read from the curve. Owing to hysteresis, the error of any velocity is considered to be $0.1 \mathrm{~km} / \mathrm{sec}$, although it was generally less than this. The actual uncertainty of individual measurements is much smaller. Examination of the data suggests several striking points. The depths 


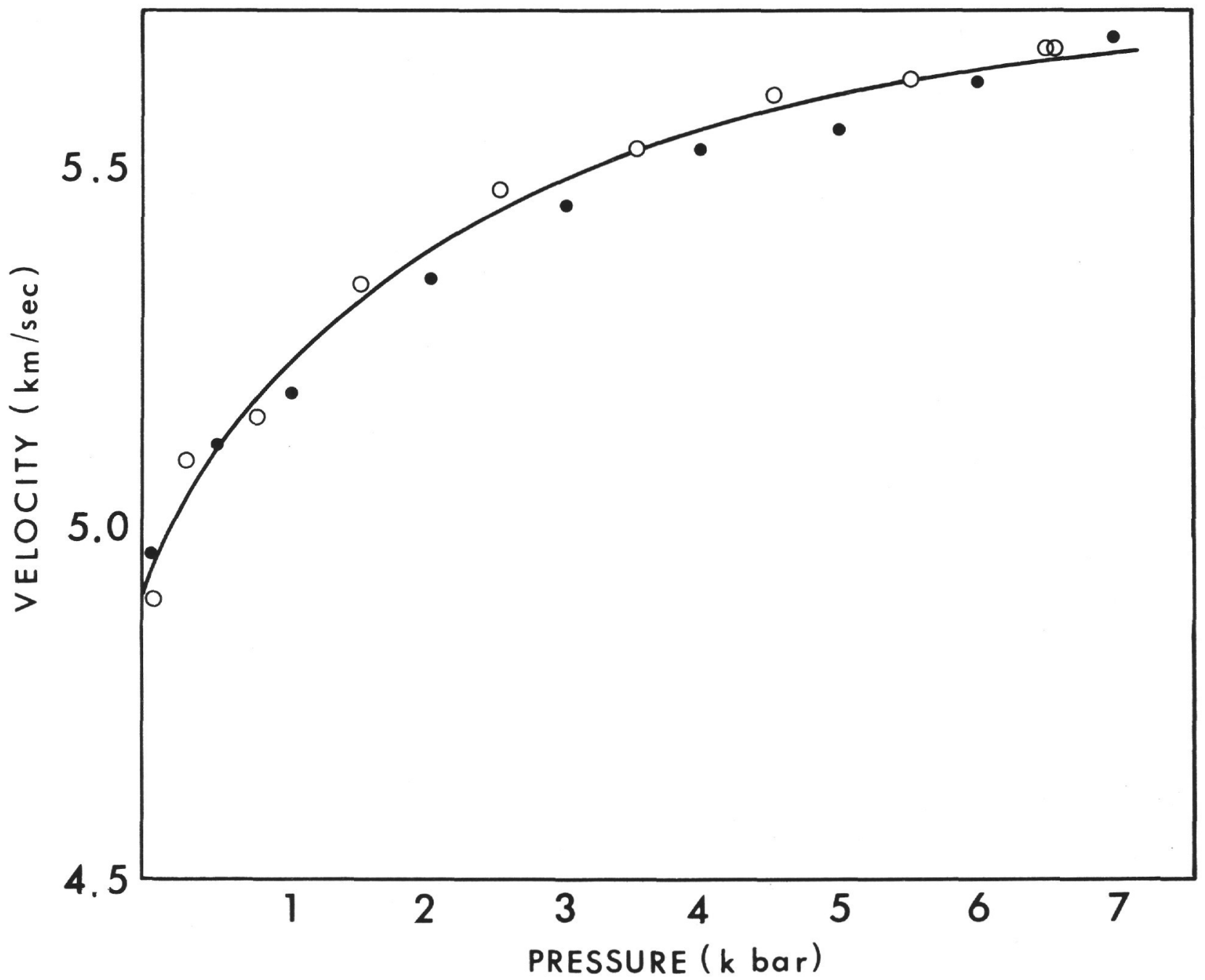

Figure 2. Compressional wave velocities for a specimen of basalt as a function of pressure. The circles indicate measurements with increasing pressure; dots with decreasing pressure.

in the crust at which these cores were taken correspond to confining pressures of 0.5 to 10 kilobars. The velocities measured for these basalts under a pressure comparable to the in situ conditions range from 3.85 to $5.79 \mathrm{~km} / \mathrm{sec}$ and are compatible with values obtained for layer 2 by seismic refraction techniques (Raitt, 1963). This is in contrast to results obtained for young basalts dredged from escarpments of the median valley of the mid-Atlantic Ridge which yielded considerably higher average compressional velocities (Christensen, 1970).

Another striking feature is the significant difference between the average velocities over the lengths of the cores from the two sites. The average velocity of basalt samples from Site 105 is $0.67 \mathrm{~km} / \mathrm{sec}$ higher than the average velocity of samples from Site 100; this suggests the possibility of lateral variation in velocity with little change in composition.
Some of the specimens exhibit anisotropy. Comparing velocities measured in specimens parallel to the drilling axis, with velocities in those specimens perpendicular to the drilling axis, we find that in some instances the velocity is higher in the direction parallel to the drilling axis, while in other instances the velocity is higher normal to the drilling axis. Unfortunately, too few samples have been measured to determine whether a pattern exists. The effect may be due either to mineral grain orientation or to micro-fracture orientation. The reason for this anisotropy will not be established until detailed microscopic examinations of the specimens are made.

The results obtained on the semi-indurated sediment specimens are shown in Table 4, where velocity is tabulated as a function of pressure. The velocities, as was expected, are all significantly lower than those found for the basalts. Although the velocities increase 
TABLE 3

Summary of Compressional Velocities

\begin{tabular}{llllllllll}
\hline & \multicolumn{7}{c}{ Pressure (k bars) } \\
\hline Sample & 0.5 & 1.0 & 1.5 & 2.0 & 2.5 & 3.0 & 4.0 & 5.0 & 6.0 \\
\hline $100-11-1 \mathrm{~A}$ & 3.85 & 3.91 & 3.98 & 4.08 & 4.21 & 4.19 & 4.32 & 4.40 & 4.49 \\
$100-12-1 \mathrm{~A}$ & 5.35 & 5.39 & 5.44 & 5.47 & 5.50 & 5.54 & 5.58 & 5.64 & 5.70 \\
$100-12-1 \mathrm{~B}$ & 4.35 & 4.40 & 4.49 & 4.54 & 4.59 & 4.65 & 4.74 & 4.83 & 4.91 \\
$100-13-1 \mathrm{~A}$ & 4.25 & 4.34 & 4.42 & 4.49 & 4.56 & 4.62 & 4.75 & 4.85 & 4.94 \\
$100-13-1 \mathrm{~B}$ & 5.05 & 5.10 & 5.15 & 5.18 & 5.22 & 5.24 & 5.28 & 5.33 & 5.38 \\
$100-13-2 \mathrm{~A}$ & 4.58 & 4.63 & 4.68 & 4.72 & 4.75 & 4.80 & 4.86 & 4.95 & 5.00 \\
$100-13-2 \mathrm{~B}$ & 4.90 & 4.94 & 4.97 & 5.01 & 5.04 & 5.08 & 5.14 & 5.21 & 5.27 \\
$105-41-1 \mathrm{~A}$ & 5.11 & 5.21 & 5.27 & 5.33 & 5.39 & 5.43 & 5.51 & 5.58 & 5.62 \\
$105-41-1 \mathrm{~B}$ & 5.60 & 5.72 & 5.77 & 5.80 & 5.83 & 5.86 & 5.91 & 5.94 & 5.98 \\
$105-41-3 \mathrm{~A}$ & 5.59 & 5.62 & 5.64 & 5.71 & 5.72 & 5.74 & 5.76 & 5.72 & 5.73 \\
$105-41-3 \mathrm{~B}$ & 5.04 & 5.15 & 5.22 & 5.29 & 5.34 & 5.39 & 5.47 & 5.53 & 5.58 \\
$105-42-2 \mathrm{~A}$ & 5.73 & 5.79 & 5.82 & 5.85 & 5.87 & 5.89 & 5.91 & 5.93 & 5.95 \\
$105-43-2 \mathrm{~A}$ & 4.82 & 4.90 & 4.98 & 5.04 & 5.10 & 5.15 & 5.23 & 5.27 & 5.31 \\
$105-43-2 \mathrm{~B}$ & 5.00 & 5.07 & 5.12 & 5.17 & 5.22 & 5.24 & 5.30 & 5.36 & 5.40 \\
\hline & & & & & & & & &
\end{tabular}

TABLE 4

Summary of Compressional Velocities for Sediments

\begin{tabular}{|c|c|c|c|c|c|c|c|c|c|}
\hline \multirow[b]{2}{*}{ Sample } & \multicolumn{9}{|c|}{ Pressure (k bars) } \\
\hline & 0.5 & 1.0 & 1.5 & 2.0 & 2.5 & 3.0 & 4.0 & 5.0 & 6.0 \\
\hline $100-3-1 \mathrm{~A}$ & 2.85 & 2.96 & 3.07 & 3.16 & 3.25 & 3.32 & 3.46 & 3.60 & 3.71 \\
\hline $100-7-1 \mathrm{~A}$ & 2.47 & 2.56 & 2.66 & 2.75 & 2.85 & 2.91 & 3.05 & 3.17 & 3.30 \\
\hline $100-8-3 A$ & 2.39 & 2.57 & 2.72 & 2.84 & 2.94 & 3.02 & 3.16 & 3.29 & 3.42 \\
\hline $105-17-3 \mathrm{~A}$ & 2.08 & 2.18 & 2.28 & 2.39 & 2.47 & 2.54 & 2.69 & 2.83 & 2.98 \\
\hline $105-17-3 B$ & 2.41 & 2.60 & 2.71 & 2.81 & 2.92 & 3.01 & 3.16 & 3.28 & 3.38 \\
\hline $105-25-2 \mathrm{~A}$ & 1.96 & 2.06 & 2.15 & 2.24 & 2.32 & 2.38 & 2.55 & 2.70 & 2.86 \\
\hline $105-25-2 B$ & 2.70 & 2.80 & 2.85 & 2.90 & 2.94 & 2.98 & 3.06 & 3.10 & 3.12 \\
\hline $105-33-1 \mathrm{~A}$ & 1.60 & 1.70 & 1.79 & 1.86 & 1.91 & 1.95 & 2.03 & 2.11 & 2.19 \\
\hline $105-35-4 \mathrm{~A}$ & 1.93 & 2.04 & 2.14 & 2.24 & 2.33 & 2.42 & 2.58 & 2.71 & 2.83 \\
\hline $105-39-1 \mathrm{~A}$ & 2.26 & 2.38 & 2.49 & 2.59 & 2.68 & 2.77 & 2.92 & 3.08 & 3.20 \\
\hline
\end{tabular}


from their initial values by about 50 per cent they remain quite low at 6 kilobars, and are much lower than the velocities reported for indurated limestones and dolomites of continental origins as summarized in Anderson and Liebermann (1966). This effect is probably due to the amount of water that was present in our samples, which are quite porous. The presence of this water within the pore structure would raise the pore pressure in proportion to the applied hydrostatic load, and inhibit or prevent the closure of pores, as occurs in the case of the basalt specimens. Consequently, the effect of pressure on the velocities is less than would be obtained if the specimens were dry. However, we believe that our experimental conditions more closely duplicate the effects of pressure due to increasing sediment load as would occur in situ, and therefore would be representative, at least to depths equivalent to pressures of 0.5 to 1 kilobars. This is in contrast to results on similar high porosity, high permeability lunar microbreccias which were dry, and exhibited a very remarkable increase in compressional velocity from values of approximately $2 \mathrm{~km} / \mathrm{sec}$ to $4-5$ $\mathrm{km} / \mathrm{sec}$ under a hydrostatic load of less than 1 kilobar (Schreiber et al., 1970).

Four samples were found to have initial compressional velocities $2 \mathrm{~km} / \mathrm{sec}$ or less, and one (Sample 100/33/A) had a value as low as $1.60 \mathrm{~km} / \mathrm{sec}$. In the two cases where samples were taken perpendicular to the axis of the core, a marked anisotropy was observed. We tentatively attribute this anisotropic effect to grain orientation probably resulting from the mode of deposition. Whether this is actually the case remains in some doubt until results of detailed microscopic examination of the specimens are available. The variation of velocities observed along the core would not significantly effect seismic refraction results because the wave lengths of compressional sound used in seismic refraction are long compared to our sampling lengths, and these wave lengths would average the observed velocity variations. On the basis of our present sampling, no significant correlations between age and observed velocity could be made. This, however, may not hold as additional data from different core locations are compiled.

\section{Acknowledgements}

The authors wish to express their appreciation to John Ewing and Charles Hollister for providing us with the opportunity to study specimens from Leg 11 . Support for this work came from the Research Foundation, City University of New York (E.S.); the National Science Foundation and Office of Naval Research (P.J.F.).

\section{REFERENCES}

Anderson, O. L. and Liebermann, R. C., 1968. Sound velocities in rocks and minerals: Experimental methods, extrapolations to very high pressures, and results. W. P. Mason (Ed), Vol. 4, Part 13. Physical A coustics. New York (Academic Press), 330.

Birch, F., 1960. The velocity of compressional curves in rocks to $10 \mathrm{k}$ bars. Part I. J. Geophys. Res. 65, 1083 .

Christensen, N. and Shaw, G., 1970. Elasticity of mafic rocks from the mid-Atlantic Ridge. Geol. J., Roy. Astro. Soc. 20, 271.

Mattaboni, P. and Schreiber, E., 1967. Method of pulse transmission measurements for determining sound velocities. J. Geophys. Res. 72, 5160.

Raitt, R. W., 1963. The Crustal Rocks in the Sea. In The Sea. M. N. Hill, (Ed.) New York (Interscience), III, 85 .

Schreiber, E., Anderson, O. L., Soga, N., Warren, N. and Scholz, C., 1970. Sound velocity, compressibility for Lunar rocks 17 and 46, and for glass spheres from the lunar soil. Science. 167, 732.

Walsh, J., 1965. The effects of cracks on the compressibility of rocks. J. Geophys. Res. 70, 381.

Warren, N., 1969. Elastic constants versus porosity for a highly porous ceramic perlite. J. Geophys. Res. 74,713 . 